\title{
Characterization of $\mathrm{BCl}_{3} / \mathrm{N}_{2}$ plasmas
}

\author{
Karen J. Nordheden ${ }^{\text {a) }}$ and Joanne F. Sia \\ Plasma Research Laboratory, Department of Chemical and Petroleum Engineering, University of Kansas, \\ Lawrence, Kansas 66045
}

(Received 25 April 2003; accepted 20 May 2003)

\begin{abstract}
Optical emission spectroscopy, quadrupole mass spectrometry, and electron density measurements were used to study the effect of the percentage of $\mathrm{N}_{2}$ on the characteristics of $\mathrm{BCl}_{3} / \mathrm{N}_{2}$ plasmas and their resulting etch processes. The etch rate of GaAs increased from $80 \AA / \mathrm{min}$ in pure $\mathrm{BCl}_{3}$ to over $1000 \AA / m i n$ in a 40:60 $\mathrm{BCl}_{3}: \mathrm{N}_{2}$ mixture $(15 \mathrm{mTorr}, 50 \mathrm{~W}, 20 \mathrm{sccm})$. The optical emission intensities of both molecular and atomic chlorine exhibited maxima near $30 \% \mathrm{~N}_{2}$, and an argon actinometer indicated a large increase in argon emission as a function of the increase in $\mathrm{N}_{2}$ percentage. Microwave measurements indicated that the average electron density increased only slightly with an increase in nitrogen percentage up to $60 \% \mathrm{~N}_{2}$. Mass spectrometric analysis of the plasmas showed that both the dissociation of $\mathrm{BCl}_{3}$ and the production of molecular chlorine were significantly enhanced by the addition of $\mathrm{N}_{2}$. These results suggest that an increase in the electron temperature as a result of electron attachment heating (and possibly energy transfer from $\mathrm{N}_{2}$ metastables) is responsible for the increased dissociation and enhanced production of etch species. (C) 2003 American Institute of Physics. [DOI: 10.1063/1.1591075]
\end{abstract}

\section{INTRODUCTION}

Gas mixtures of boron trichloride and nitrogen have been used to etch a variety of materials. Howard and Steinbruchel reported the use of $\mathrm{BCl}_{3} / \mathrm{N}_{2}$ mixtures for the reactive ion etching of copper. ${ }^{1}$ They found that the addition of nitrogen to $\mathrm{BCl}_{3}$ plasmas resulted in considerably higher copper etch rates, and observed a maximum etch rate at $30 \%$ nitrogen. Their optical spectroscopy results showed that the addition of $\mathrm{N}_{2}$ increased the atomic $\mathrm{Cl}$ emission. They also observed the presence of $\mathrm{BN}$ emission and suggested that the increased chlorine concentrations were due to the scavenging of boron by nitrogen to produce $\mathrm{BN}$, thus preventing the recombination of atomic chlorine.

High etch rates for InGaP and $\mathrm{InP}$ were reported in electron cyclotron resonance (ECR) generated $\mathrm{BCl}_{3} / \mathrm{N}_{2}$ plasmas at $100^{\circ} \mathrm{C}$ by Ren et al. ${ }^{2}$ The maximum etch rate occurred at a composition of $25 \%$ nitrogen. Using optical emission spectroscopy, they found increases in the intensities of $\mathrm{Cl}$ and $\mathrm{Cl}_{2}^{+}$emission as well as the presence of BN emission. Shul et al. observed enhancement in the etch rates of GaAs, GaP, and $\mathrm{GaN}$ with the addition of $\mathrm{N}_{2}$ to $\mathrm{BCl}_{3}$ plasmas. ${ }^{3,4}$ Optimum etch rates were observed at $25 \% \mathrm{~N}_{2}$ for GaAs and $\mathrm{GaP}$ in an ECR system, ${ }^{3}$ and at $40 \% \mathrm{~N}_{2}$ for GaN in an inductively coupled plasma (ICP) system. ${ }^{4}$ Optical emission spectroscopy of the gas mixtures was performed and they found that their observations were in contradiction with those of Ren et $a .^{2}$ They were unable to identify $\mathrm{BN}$ emission or increased emissions for atomic or molecular chlorine. ${ }^{4}$ Fedision et al. have also used $\mathrm{BCl}_{3} / \mathrm{N}_{2}$ plasmas to reactively ion etch $\mathrm{GaN}^{5}$ Their results indicated that the maximum etch rate of $\mathrm{GaN}$ occurred when $25 \% \mathrm{~N}_{2}$ was added to $\mathrm{BCl}_{3}$ plasmas.

${ }^{a)}$ Electronic mail: nordhed@ku.edu
A review of the literature on etch processes with $\mathrm{BCl}_{3} / \mathrm{N}_{2}$ plasmas reveals that there are still uncertainties as to the actual mechanism responsible for the enhanced chlorine production. Optical emission spectroscopy has been used to characterize this gas mixture but some data are contradictory. In this work we attempt to provide an in depth characterization of $\mathrm{BCl}_{3} / \mathrm{N}_{2}$ plasmas using optical emission spectroscopy (OES), quadrupole mass spectrometry (QMS), and microwave measurements of average electron densities.

\section{EXPERIMENTAL PROCEDURE}

The experiments described in this work were performed in a PlasmaTherm 790 parallel-plate reactive ion etch (RIE) system. The 10 in. diam aluminum powered electrode was operated at a frequency of $13.56 \mathrm{MHz}$. The upper electrode and chamber walls were grounded, and the top electrode was located approximately 3 in. above the powered electrode. The chamber was evacuated around the outer diameter of the powered electrode by a $150 \mathrm{l} / \mathrm{s}$ water-cooled turbo pump backed by a $32 \mathrm{cfm}$ mechanical pump. Gases were introduced into the plasma chamber through a showerhead configuration in the top of the chamber, and were controlled by MKS mass flow controllers. Before etching, the chamber was evacuated to a base pressure of less than 1 $\times 10^{-5}$ Torr, and during etching the chamber pressure was kept constant with a throttle valve.

Etch studies were conducted on $1 \mathrm{~cm} \times 1 \mathrm{~cm}$ full thickness GaAs mechanical wafer pieces which were patterned with AZ4210 photoresist. Prior to loading the samples into the RIE chamber, they were baked on a hot plate at $90^{\circ} \mathrm{C}$ for 1 min to enhance the etch resistance of the photoresist, then an oxide etch was performed in 1:30 solution of $\mathrm{NH}_{4} \mathrm{OH} / \mathrm{H}_{2} \mathrm{O}$ for $15 \mathrm{~s}$, followed by blow drying with nitrogen. Etched depths were measured with a DekTak surface 
profilometer after removal of the photoresist mask. The etch profile and morphology were examined using a scanning electron microscope (SEM).

The microwave measurement system used to monitor electron density consisted of a network analyzer (HP8722C) which was used to generate and detect the $32 \mathrm{GHz}$ microwave signal. Details of the operating procedure are described elsewhere ${ }^{6}$ only a brief description is provided here. The output from the network analyzer was coupled to a collimating antenna mounted flush to the Pyrex window of the plasma chamber with a high-quality radio-frequency (rf) cable. A similar antenna mounted at the other end of the chamber collected signals transmitted through the chamber. These signals are coupled to the network analyzer input port though another high-quality rf cable. The phase of the transmitted signal was measured with and without a plasma and the difference of these was used to obtain the phase shift experienced by the signal in propagating though the plasma. The line-averaged electron density was then calculated from this excess phase shift. ${ }^{7}$

Optical emission from the discharge was focused with a fused silica lens onto the slits of a Jobin-Yvon Spex Triax 550 spectrometer and detected with a Hamamatsu R928 photomultiplier. The entrance and exit slits of the spectrometer were $100 \mu \mathrm{m}$. The $750 \mathrm{~nm}$ argon emission line was chosen as an actinometer since it has been shown to be excited directly from the ground state and does not have a significant contribution from the argon metastable state. ${ }^{8}$

The $600 \mathrm{amu}$ VG Quadropoles SXP Elite mass spectrometry system was connected to the PlasmaTherm 790 reactor chamber via one of the viewports. Discharge species were sampled through a $100 \mu \mathrm{m}$ diam orifice, and sampling pressures within the mass spectrometer were on the order of $10^{-7}$ Torr to reduce recombination reactions within the analyzer. The emission current of the spectrometer was set below $0.3 \mathrm{~mA}$ to minimize the effect of thermal dissociation of neutral species caused by hot electron emission from the filament. To insure that the mass signals originated only from neutrals in the plasma, and not from dissociative ionization within the mass spectrometer itself, appearance mass spectrometry was employed. ${ }^{9}$ This technique is based on the several electron volt energy difference between the appearance potentials for electron-impact ionization and the energy for dissociative ionization of parent molecules. For radicals such as $\mathrm{BCl}_{2}, \mathrm{Cl}_{2}$, and $\mathrm{Cl}$ the electron energy was set below the threshold appearance energy needed to observe the mass signal with the plasma off. An electron energy of $35 \mathrm{eV}$ was used to monitor $\mathrm{BCl}_{3}$ for dissociation measurements.

\section{RESULTS AND DISCUSSION}

The GaAs etch rate at $15 \mathrm{mTorr}$ as a function of the percentage of $\mathrm{N}_{2}$ in $\mathrm{BCl}_{3} / \mathrm{N}_{2}$ plasmas is shown in Fig. 1 . The total flow and rf power were held constant at $20 \mathrm{sccm}$ and $50 \mathrm{~W}$, respectively. The corresponding dc bias is also shown. The etch rate increases from $80 \AA / m i n$ in pure $\mathrm{BCl}_{3}$ to $1070 \AA / \mathrm{min}$ at $60 \% \mathrm{~N}_{2}$. The bias voltage shows a slight increase with the addition of up to $80 \% \mathrm{~N}_{2}$, and it is possible that a small fraction of the etch rate enhancement observed is

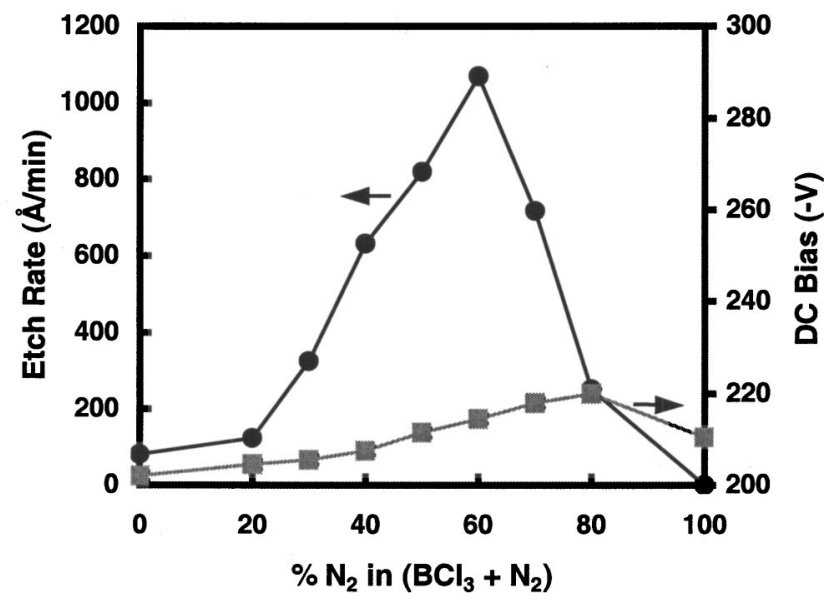

FIG. 1. Etch rate of GaAs in $\mathrm{BCl}_{3} / \mathrm{N}_{2}$ plasmas with the percentage of $\mathrm{N}_{2}$ in the flow as a parameter $(50 \mathrm{~W}, 15 \mathrm{mTorr}$, and $20 \mathrm{sccm})$. The dc bias voltage is also shown.

due to an increase in physical bombardment. SEM micrographs of a GaAs sample etched at $50 \mathrm{~W}$ and $60 \% \mathrm{~N}_{2}$ are shown in Fig. 2. The etched surfaces are quite smooth and anisotropic. Some vertical striations are apparent on the sidewalls which are believed to be due to imperfections in the photoresist mask.

The optical emission intensities for atomic chlorine, molecular chlorine, and argon are shown in Fig. 3 as a function of the percentage of $\mathrm{N}_{2}$ in the flow for a constant rf power of $50 \mathrm{~W}$. The excited state emission from $\mathrm{Cl}$ and $\mathrm{Cl}_{2}^{+}$increases with an increase in $\mathrm{N}_{2}$ and both exhibit maxima at approximately $30 \% \mathrm{~N}_{2}$. No evidence of $\mathrm{BN}$ emission was apparent. Argon was added to the gas mixture (2 sccm) as an actinometer, and its excited state emission increased significantly with the addition of $\mathrm{N}_{2}$. Since the ground state concentration of argon is constant (constant flow rate), the increase in its emission is an indication of a significant change in the electron density and/or the electron temperature.

The average electron density as a function of the applied rf power is shown in Fig. 4 for pure $\mathrm{N}_{2}$, pure $\mathrm{BCl}_{3}$, and a mixture of $50 \% \mathrm{~N}_{2}$ in $\mathrm{BCl}_{3}$. The pressure and flow rate were held constant at $15 \mathrm{mTorr}$ and $20 \mathrm{sccm}$, respectively. For each plasma, the electron density increases with an increase in the rf power applied, and the overall electron density in pure nitrogen is higher than for pure $\mathrm{BCl}_{3}$ or the $50 \% \mathrm{~N}_{2}$ mixture. At lower rf powers, the electron density of the $50 \%$ $\mathrm{N}_{2}$ mixture is almost the same as that of the pure $\mathrm{BCl}_{3}$
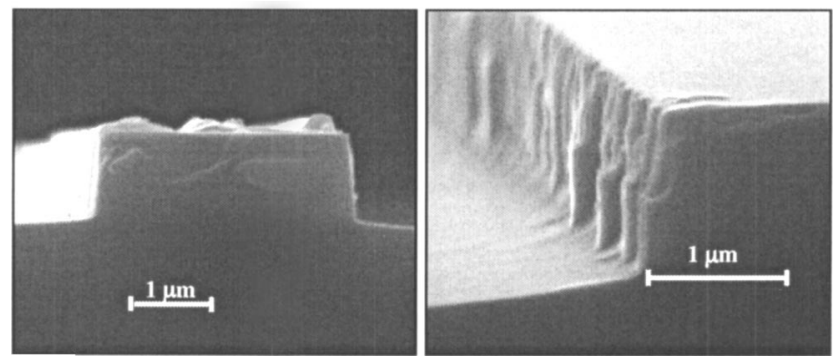

FIG. 2. SEM micrographs of GaAs etched with $60 \% \mathrm{~N}_{2}$ in a $\mathrm{BCl}_{3} / \mathrm{N}_{2}$ plasma (15 mTorr, $50 \mathrm{~W}, 20 \mathrm{sccm}, 5 \mathrm{~min})$. 


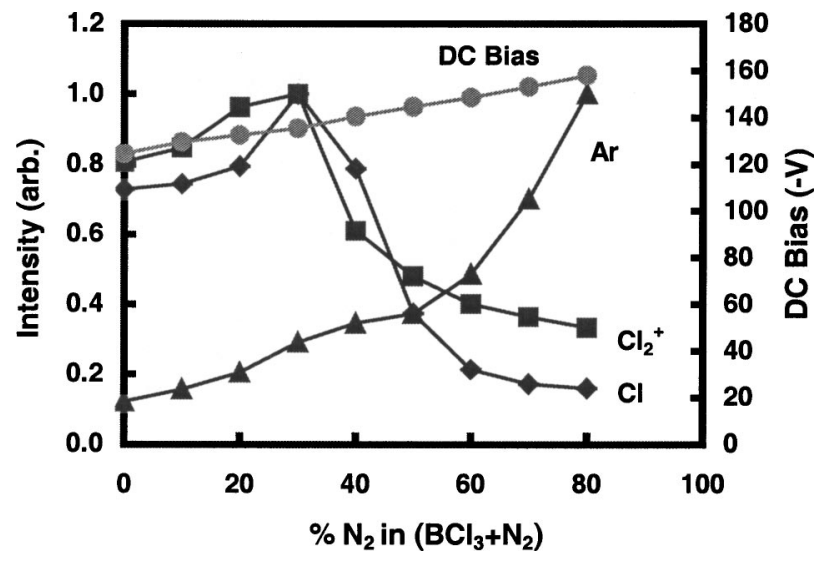

FIG. 3. Normalized optical emission intensities of $\mathrm{Ar}(750.4 \mathrm{~nm}), \mathrm{Cl}_{2}^{+}$ $(396.2 \mathrm{~nm})$, and $\mathrm{Cl}(792.5 \mathrm{~nm})$ as a function of the percentage of $\mathrm{N}_{2}$ in the flow for $\mathrm{BCl}_{3} / \mathrm{N}_{2}$ plasmas [50 mTorr, $50 \mathrm{~W}, 20 \mathrm{sccm}\left(\mathrm{BCl}_{3}+\mathrm{N}_{2}\right), 2 \mathrm{sccm}$ $\mathrm{Ar}]$. The dc bias is also shown.

plasma, and as the rf power increases, the $50 \% \mathrm{~N}_{2}$ mixture has a slightly higher electron density than the pure $\mathrm{BCl}_{3}$ plasma. The fact that the average electron density does not significantly increase with the addition of electropositive $\mathrm{N}_{2}$ is an indication that electron attachment occurs.

The average electron density and dc bias voltage are shown as functions of nitrogen percentage in Fig. 5. The rf power, pressure, and total flow rate were held constant at 100 $\mathrm{W}, 15 \mathrm{mTorr}$, and $20 \mathrm{sccm}$, respectively. There was less than a $20 \%$ increase in the average electron density as the percentage of nitrogen was increased from $0 \%$ to $60 \%$. From Fig. 1, over this same range of nitrogen (and only half the rf power), the etch rate increased by more than a factor of 10 . Above $60 \% \mathrm{~N}_{2}$, the electron density rises rapidly to the pure $\mathrm{N}_{2}$ plasma electron density which is more than three times that of pure $\mathrm{BCl}_{3}$. The dc bias also increased with an increase in $\mathrm{N}_{2}$ up to $80 \% \mathrm{~N}_{2}$, then decreased for pure $\mathrm{N}_{2}$. The combined effect of the increase of electron density and the increase in dc bias is not likely to be sufficient to account for the magnitude of etch rate enhancement observed. Fleddermann and Hebner reported that the electron density in their

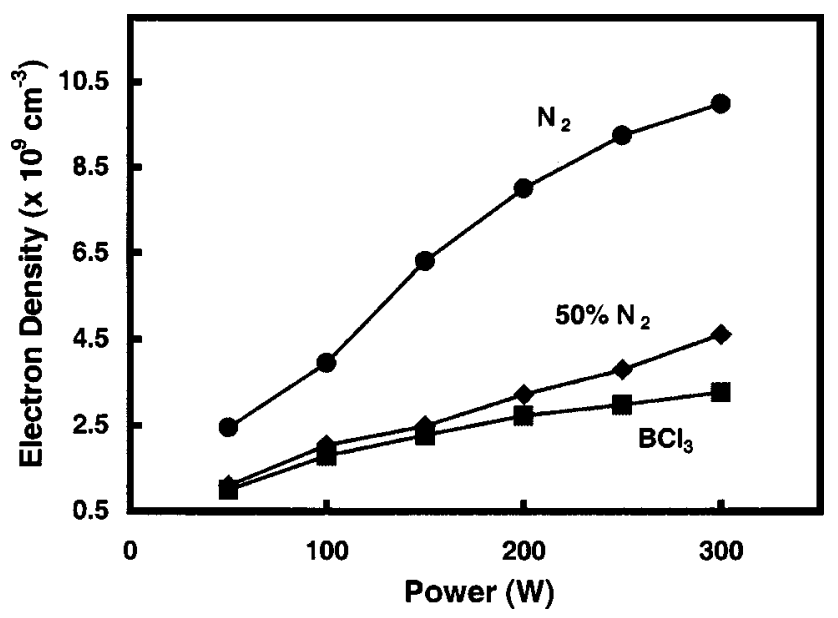

FIG. 4. Average electron density as a function of the applied rf power for $\mathrm{N}_{2}, 50 \% \mathrm{~N}_{2}$ in $\mathrm{BCl}_{3}$, and $\mathrm{BCl}_{3}$ plasmas (15 mTorr, $20 \mathrm{sccm}$ ).

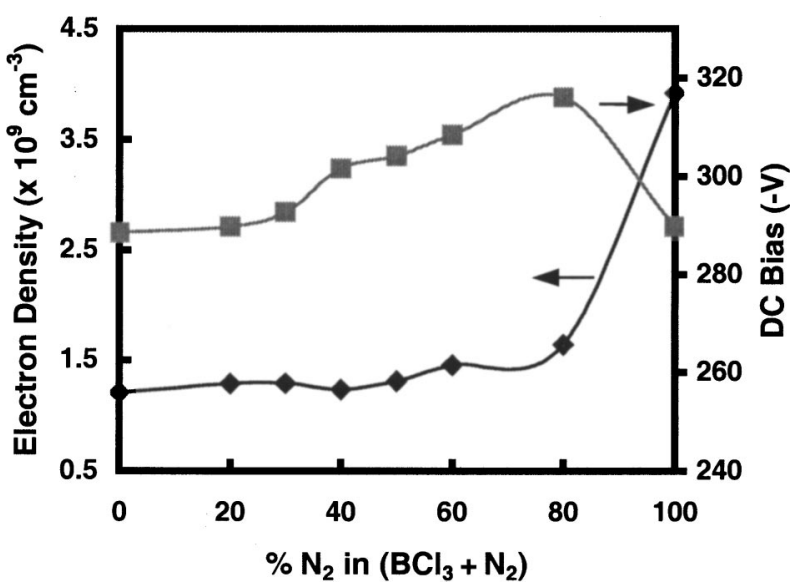

FIG. 5. Average electron density as a function of the percentage of $\mathrm{N}_{2}$ in $\mathrm{BCl}_{3} / \mathrm{N}_{2}$ plasmas (15 mTorr, $20 \mathrm{sccm}, 100 \mathrm{~W}$ ).

ICP system did not change as nitrogen was added to $\mathrm{BCl}_{3}$, but the negative atomic chlorine ion $\left(\mathrm{Cl}^{-}\right)$density doubled. ${ }^{10}$ It is plausible that electron attachment heating might be responsible for an increase in the production of etch species.

The QMS intensities of $\mathrm{BCl}_{2}, \mathrm{BCl}, \mathrm{Cl}_{2}$, and $\mathrm{Cl}$ as a function of the percentage of $\mathrm{N}_{2}$ in the flow are shown in Fig. 6. The rf power, pressure, and total flow rate were held constant at $100 \mathrm{~W}, 50 \mathrm{mTorr}$, and $20 \mathrm{sccm}$, respectively. No mass signal was detected for $\mathrm{BN}$. The $\mathrm{Cl}_{2}$ intensity increased to three times its value for pure $\mathrm{BCl}_{3}$ at approximately $80 \%$ $\mathrm{N}_{2}$, and the $\mathrm{Cl}$ intensity decreased but exhibited a local maximum at $80 \% \mathrm{~N}_{2}$. Recombination of $\mathrm{Cl}$ to form $\mathrm{Cl}_{2}$ during transport to the mass spectrometer most likely accounts for the low $\mathrm{Cl}$ intensity. The difference in the percentage of $\mathrm{N}_{2}$ where the maximum etch rate occurs (15 mTorr) and the molecular chlorine mass signal peaks (50 mTorr) is probably due to the increase in pressure which was necessary to have adequate mass signals. In fact, Fedison et al. ob-

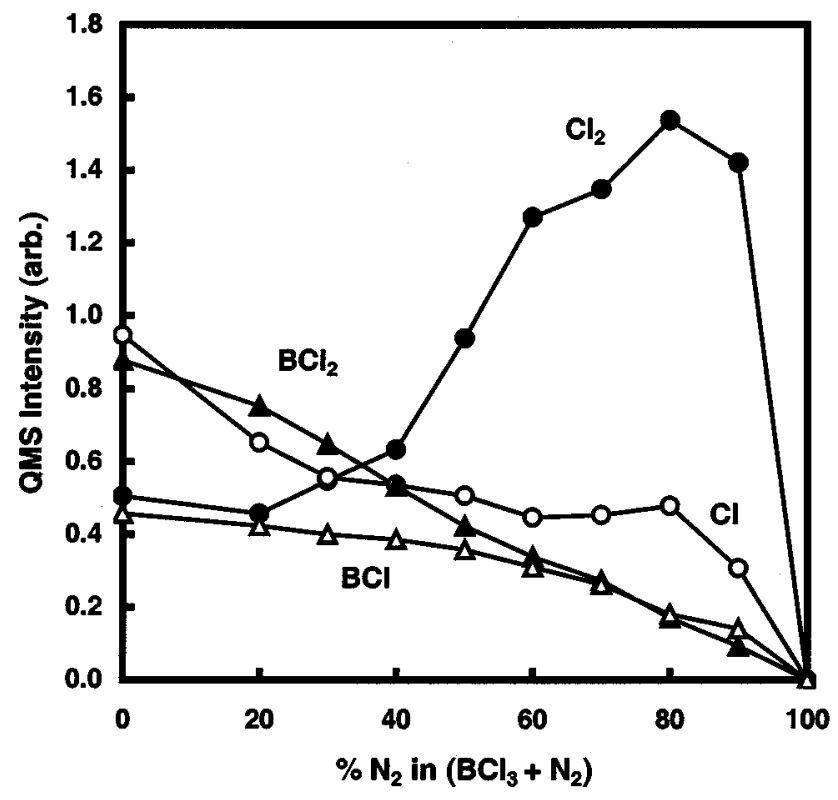

FIG. 6. QMS intensities of $\mathrm{BCl}_{2}, \mathrm{BCl}, \mathrm{Cl}_{2}$, and $\mathrm{Cl}$ as a function of the percentage of $\mathrm{N}_{2}$ in $\mathrm{BCl}_{3} / \mathrm{N}_{2}$ plasmas (100 W, 50 mTorr, $20 \mathrm{sccm}$ ). 


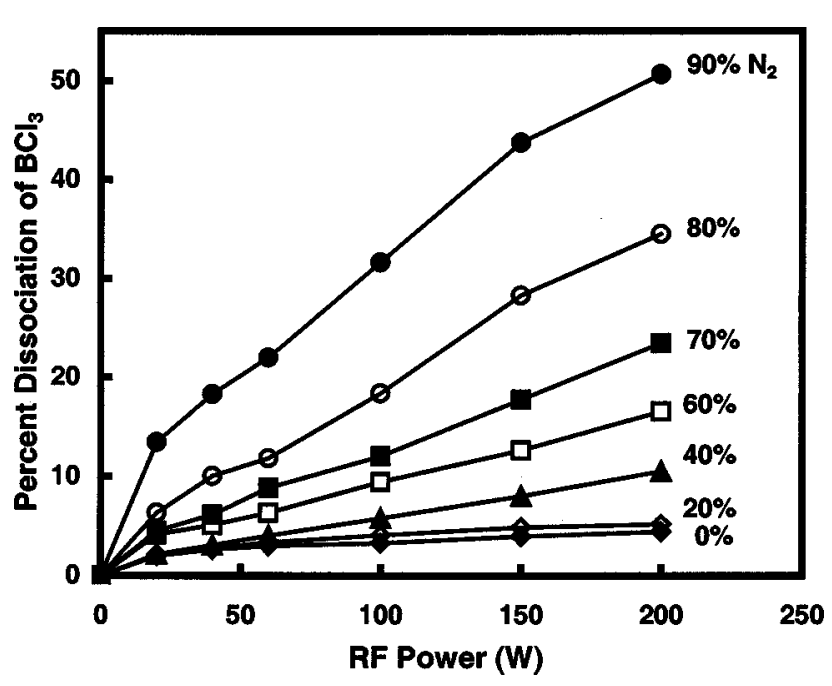

FIG. 7. Dissociation of $\mathrm{BCl}_{3}$ as a function of the applied rf power with the percentage of $\mathrm{N}_{2}$ as a parameter in $\mathrm{BCl}_{3} / \mathrm{N}_{2}$ plasmas (50 mTorr, $20 \mathrm{sccm}$ ).

served that the maximum GaN etch rate shifted toward higher $\mathrm{N}_{2}$ percentages as the pressure was increased. ${ }^{5}$

The dissociation of $\mathrm{BCl}_{3}$ was measured as a function of the applied rf power with the percentage of $\mathrm{N}_{2}$ as a parameter and the results are shown in Fig. 7. The pressure of the system was held constant at 50 mTorr and the flow rate was maintained at $20 \mathrm{sccm}$. The dissociation of $\mathrm{BCl}_{3}$ is defined as the difference in QMS intensity of the $\mathrm{BCl}_{3}$ signal with the plasma on and off, divided by the intensity while off. The dissociation of $\mathrm{BCl}_{3}$ increased with an increase in rf power regardless of the percentage of $\mathrm{N}_{2}$ in the flow. This is consistent with the fact that higher $\mathrm{rf}$ power results in higher electron densities, which should enhance the dissociation of $\mathrm{BCl}_{3}$. For the $0 \% \mathrm{~N}_{2}$ curve, the dissociation of $\mathrm{BCl}_{3}$ is very low and shows only a slight increase with an increase in $\mathrm{rf}$ power. Even at a rf power of $200 \mathrm{~W}$, the dissociation of pure $\mathrm{BCl}_{3}$ was only $4.4 \%$, which explains the very low etch observed in Fig. 1. For constant rf power, the dissociation of $\mathrm{BCl}_{3}$ increased dramatically with an increase in the percentage of $\mathrm{N}_{2}$. At $90 \% \mathrm{~N}_{2}$ and power of $200 \mathrm{~W}$, the dissociation of $\mathrm{BCl}_{3}$ was almost $50 \%$.

\section{SUMMARY}

The etch rate of GaAs increases dramatically with the addition of nitrogen to $\mathrm{BCl}_{3}$ plasmas. Mass spectrometric analysis indicates that the etch rate enhancement is due to an increase in the dissociation of $\mathrm{BCl}_{3}$, and a subsequent increase in the production of etch species. Although the average electron density and dc bias voltage increase slightly with an increase in the percentage of nitrogen, it is unlikely that they alone account for the increase in etch rate. Optical emission from an argon actinometer increased significantly, and electron density measurements indicated that electron attachment occurred. These results suggest that an increase in the electron temperature as a result of electron attachment heating (and possibly energy transfer from $\mathrm{N}_{2}$ metastables) is responsible for the increased dissociation and enhanced production of etch species.

\section{ACKNOWLEDGMENTS}

This work was supported by the National Science Foundation under Grant No. EPS-9977776, and matching support from the State of Kansas. The authors would like to thank TriQuint Semiconductor, Richardson, Texas, for supplying the GaAs substrates, and S. P. Gogineni for use of the network analyzer.

${ }^{1}$ B. J. Howard and Ch. Steinbruchel, J. Vac. Sci. Technol. A 12, 1259 (1994).

${ }^{2}$ F. Ren, W. S. Hobson, J. R. Lopata, S. J. Pearton, J. A. Caballero, and M. W. Cole, J. Electrochem. Soc. 143, 3394 (1996).

${ }^{3}$ R. J. Shul, A. B. Baca, D. J. Rieger, H. Hou, S. J. Pearton, and F. Ren, Mater. Res. Soc. Symp. Proc. 421, 245 (1996).

${ }^{4}$ R. J. Shul, R. D. Briggs, S. J. Pearton, C. B. Vartuli, C. R. Abernathy, J. W. Lee, C. Constantine, and C. Barratt, Mater. Res. Soc. Symp. Proc. 449, 969 (1997).

${ }^{5}$ J. B. Fedison, T. P. Chow, H. Lu, and I. B. Bhat, J. Electrochem. Soc. 144, L221 (1999).

${ }^{6}$ K. J. Nordheden, K. Upadhyaya, Y.-S. Lee, S. P. Gogineni, and M.-Y. Kao, J. Electrochem. Soc. 147, 3850 (2000).

${ }^{7}$ G. A. Hebner, J. T. Verdeyen, and M. J. Kushner, J. Appl. Phys. 63, 2226 (1988).

${ }^{8}$ M. V. Malyshev, V. M. Donnelly, A. Kornblit, and N. A. Ciampa, J. Appl. Phys. 84, 137 (1998).

${ }^{9}$ H. Sugai and H. Toyoda, J. Vac. Sci. Technol. A 10, 1193 (1992).

${ }^{10}$ C. B. Fleddermann and G. A. Hebner, J. Vac. Sci. Technol. A 15, 1955 (1997). 